\title{
A systematic study of the impact of freshwater pulses with respect to different geographical locations
}

\author{
Didier M. Roche - Ane P. Wiersma • \\ Hans Renssen
}

Received: 22 October 2008/Accepted: 13 April 2009/Published online: 1 May 2009

(C) The Author(s) 2009. This article is published with open access at Springerlink.com

\begin{abstract}
The first comparative and systematic climate model study of the sensitivity of the climate response under Last Glacial Maximum (LGM) conditions to freshwater perturbations at various locations that are known to have received significant amounts of freshwater during the LGM (21 kyr BP) climate conditions is presented. A series of ten regions representative of those receiving most of the meltwater from decaying ice-sheets during the deglaciation is defined, comprising the border of LGM ice-sheets, outlets of rivers draining part of the melting ice-sheets and iceberg melt zones. The effect of several given freshwater fluxes applied separately in each of these regions on regional and global climate is subsequently tested. The climate response is then analysed both for the atmosphere and oceans. Amongst the regions defined, it is found that the area close by and dynamically upstream to the main deep water formation zone in the North Atlantic are most sensitive to freshwater pulses, as is expected. However, some important differences between Arctic freshwater forcing and Nordic Seas forcing are found, the former having a longer term response linked to sea-ice formation and advection whereas the latter exhibits more direct influence of direct freshening of the deep water formation sites. Combining the common surface temperature response for each respective zone, we fingerprint the particular surface temperature response obtained by adding freshwater in a particular location. This is done to examine if
\end{abstract}

D. M. Roche $(\square) \cdot$ H. Renssen

Section Climate Change and Landscape Dynamics, Department of Earth Sciences, Vrije Universiteit Amsterdam, De Boelelaan 1085, 1081 HV Amsterdam, The Netherlands e-mail: Didier.Roche@falw.vu.nl

A. P. Wiersma

Deltares, Subsurface and Groundwater systems,

Utrecht, The Netherlands a surface climate response can be used to determine the origin of a meltwater flux, which is relevant for the interpretation of proxy data. We show that it is indeed possible to generally classify the fingerprints by their origin in terms of sea-ice modification and modification of deep-water formation. Whilst the latter is not an unambiguous characterization of each zone, it nonetheless provides important clues on the physical mechanisms at work. In particular, it is shown that in order to obtain a consistent see-saw temperature pattern, addition of freshwater in the Northern Hemisphere at sites dynamically close to the deep water formation zones is needed. Finally a preliminary data-model comparison for the time of the Heinrich event 1 suggests that those sites are indeed the most favourable to explain the pattern of climate variability recorded in proxy data for this period. More importantly, this model-data comparison enables us to clearly reject a substantial fraction of the zones tested as potential source for large freshwater entering the ocean at that time.

Keywords Last Glacial Maximum .

Freshwater perturbation · Climate modelling

\section{Introduction}

The ocean circulation in the Atlantic Ocean is widely accepted to be of crucial importance for the Northern Hemisphere climate. Indeed, the upper branch of the socalled thermohaline circulation (THC) is transporting warm and saline water to the Northern Hemisphere where it releases its heat to the atmosphere, subsequently warming the climate (Trenberth and Caron 2001). Perturbation of this system by modifying the surface buoyancy fluxes has first been recognised by Stommel (1961) as a potential 
cause for changing the ocean state. Subsequently, Broecker et al. (1988) put forward the importance of the modification of the THC in changing the surface climate, at first in the context of the Younger-Dryas cold period during the deglaciation. Since then, numerous studies have aimed at assessing the impact of imposed freshwater perturbations to the surface ocean (known as hosing experiments) in different climate models. Most studies (Rahmstorf 1995; Manabe and Stouffer 1995; Ganopolski and Rahmstorf 2001; Vellinga and Wood 2002; Stouffer et al 2006) have directed the perturbation to the North Atlantic Ocean, where the addition of freshwater modifies the deep water formation and slow down the THC. In turn, such modifications of the ocean dynamics promote drastic climate changes over (and around) the North Atlantic region. Recently, some additional studies have investigated the impact of a freshwater perturbation in the Southern Ocean (Knorr and Lohmann 2003; Stouffer et al. 2007) in order to investigate the symmetry of climate changes caused by perturbing the North Atlantic Ocean and Southern Ocean with freshwater. In addition, Peltier et al. (2006) have demonstrated that forcing the Arctic Ocean with freshwater leads to comparable results as perturbing the North Atlantic, albeit with different processes at work, in particular involving a strong sea-ice feedback. Finally, the importance of delivering freshwater to coastal regions instead of spreading it over large regions of the oceans has been investigated, showing the importance of the interplay between atmosphere and oceans (Saenko et al. 2007).

Until now however, no study has provided a comprehensive and systematic picture of the sensitivity of ocean circulation to freshwater perturbations at the various geographical regions that have been proposed as a source of freshwater eventually leading to abrupt climate events. Such a study is of crucial importance if one aims at correctly simulating the climate evolution at times when there is strong meltwater from decaying ice-sheets directed to the ocean, as was the case during the last deglaciation (21-8 kyr BP) when decaying ice-sheets were delivering huge amounts of freshwater to the ocean. Potentially, this might also be relevant for the near future, since the Greenland ice sheet is experiencing accelerated melting in response to anthropogenic warming, which is also likely to affect the balance of the West-Antarctic ice sheet.

Here we aim at providing a first step towards the comprehensive simulation of the last deglaciation by systematically studying the effect of freshwater forcing in the regions that are known to receive important freshwater contributions during the deglaciation. Therefore, we use the Last Glacial Maximum (LGM) climate as a background climatic state.

\section{Definition of the freshwater perturbation zones}

Hosing experiments focusing on the North Atlantic generally use a crude geographical spreading of the freshwater anomaly: in most case, the pulse is spread evenly over a wide longitudinal band (e.g. (Ganopolski and Rahmstorf 2001; Stouffer et al. 2006)). Although this scheme does present the advantage of being simple and can potentially be used in any climate model (including zonally averaged ocean models), it is an highly unrealistic forcing considering how most freshwater forcing enters the ocean (either today or in past climates). Therefore, if one is looking for a fruitful model data comparison, there is a need of testing the sensitivity of coupled climate models to more realistic freshwater inputs including different geographical locations.

For the purpose defined above, we need to define the various geographical zones that are known to be affected by freshwater pulses during the deglaciation. In a somewhat simplified view, there are two different classes of locations that can be defined here: one relates to areas where icebergs were calved (i.e. ice sheets oceanic margins) and where they melted, the other is constituted by river outlets draining the melting ice sheets. The first class contains all oceanic regions at the margin of LGM ice-sheets which decayed since $21 \mathrm{kyr} \mathrm{BP}$ : along the Fennoscandian ice-sheet, the Laurentide ice-sheet (both the Labrador Sea and the Pacific Ocean) and the Southern Ocean along Antarctica. The second class contains the known freshwater outlets which are receiving the routing of freshwater from the decaying icesheets: a chronology has been built for northern America (Marshall and Clarke 1999; Tarasov and Peltier 2005, 2006) based on geological evidence and numerical terrain modeling and some constraints have emerged recently on the European side (Zaragosi et al. 2001; Eynaud et al. 2007) from proximal ocean cores. Taking all these considerations into account, we define ten different geographical zones (see Fig. 1) in which freshwater can be added to the ocean. Zones representing freshwater input from ice sheets consist of multiple ocean grid cells, whereas river outlets consist of only a few coastal gridcells.

In the following we refer to these zones with the following acronyms: Fennoscandian Ice Sheet Margin (FISM), Ruddiman Belt (RB), Saint Lawrence Outlet (SLO), Hudson River Outlet (HRO), Gulf of Mexico (GoM), MacKenzie River Outlet (MRO), Labrador Sea (LS), Channel River Outlet (CRO), Laurentide Ice Sheet Margin on the Pacific side (LIMP) and Antarctic Ice Sheet Margin (AISM). 


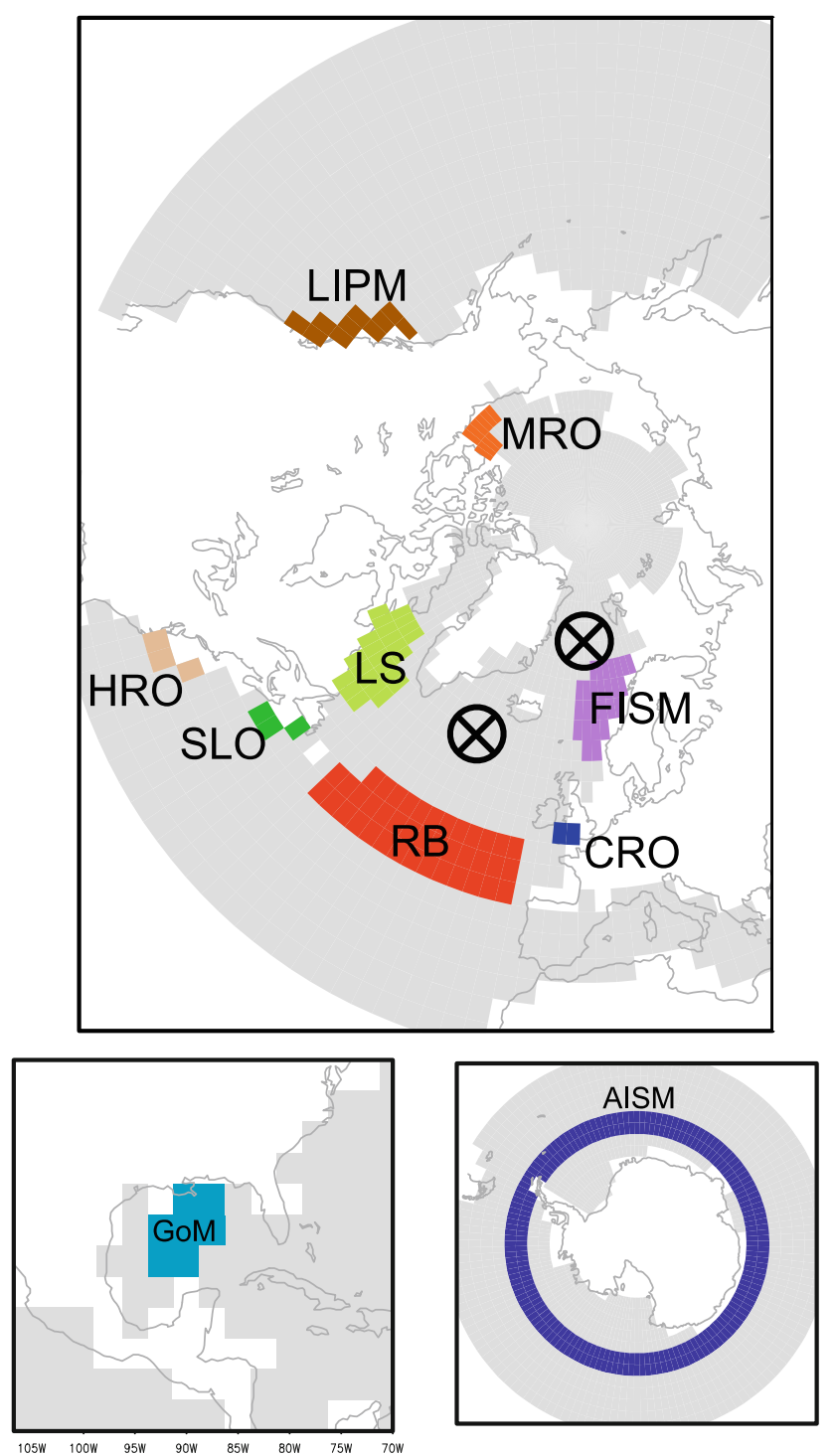

Fig. 1 Geographical location of the freshwater input zones. The ten zones are referred to by the following acronyms: Fennoscandian Ice Sheet Margin (FISM), Ruddiman Belt $(R B)$, Saint Lawrence Outlet $(S L O)$, Hudson River Outlet $(H R O)$, Gulf of Mexico $(G o M)$, MacKenzie River Outlet $(M R O)$, Labrador Sea $(L S)$, Channel River Outlet $(C R O)$, Laurentide Ice Sheet Margin on the Pacific side (LIMP) and Antarctic Ice Sheet Margin (AISM). The two circled black crosses are showing the approximate location of the northern deep water formation in our model under LGM boundary conditions

\section{Model set-up and experimental design}

\subsection{Model description}

In this study we use the three-dimensional Earth System model LOVECLIM, an acronym consisting of the names of the five contributing components: Loch (oceanic carbon cycle), Vecode (terrestrial vegetation and carbon cycle), Ecbilt (atmosphere), CLio (ocean) and agIsM (icesheets). We here only use the atmosphere-ocean-vegetation modules (equivalent to ECBilt-CLIO-VECODE version 3 ), a model already used in studies on the Holocene (Renssen et al. 2005), the last and the next millennium (Goosse et al. 2005; Driesschaert et al. 2007) or the LGM (Roche et al. 2007). The choice of this coupled model was guided by its availability and performance, allowing to compute a large ensemble of experiments in a relatively short integration time.

The atmospheric model (ECBilt) is a global quasi-geostrophic, spectral model at T21 horizontal resolution, with additional parametrizations for the diabatic heating due to radiative fluxes, the release of latent heat, and the exchange of sensible heat with the surface (Opsteegh et al. 1998). It contains a full hydrological cycle, including a simple bucket model for soil moisture over continents and run-off that is instantly distributed over a designated ocean area, corresponding to associated river catchments. The ocean module (CLIO) is a three dimensional, free-surface, general circulation model coupled to a thermodynamical and dynamical sea-ice model (Goosse and Fichefet 1999). A free-surface model enables us to apply real freshwater fluxes in our hosing experiments, not only salinity fluxes (Tartinville et al. 2001).

The vegetation module is the VECODE dynamical terrestrial vegetation model (Brovkin et al. 1997) which computes plant fractions for trees and herbaceous plants (plus desert as a dummy type) from several atmospheric variables in each land grid-cell. As we seek to assess the sensitivity of each geographical zone to freshwater input, the shape of the freshwater input with respect to time is of little importance. We have chosen, therefore, to keep the forcing as simple as possible: we simply apply a freshwater flux defined by its duration and maximum freshwater input in cSv (centi-Sverdrups, $10^{4} \mathrm{~m}^{3} \mathrm{~s}^{-1}$ ). Table 1 summarizes the experiments performed. Pulses have a duration between 100 and 400 years with associated freshwater fluxes between 10 and $30 \mathrm{cSv}$, values typical of what is estimated to be realistic for important dramatic freshwater input during the last glacial and deglaciation (e.g. Heinrich 4 (Roche et al. 2004) or Younger-Dryas (Tarasov and Peltier 2005)). The values are chosen in order for several experiments to provide the same eustatic sea level (e.s.l.) equivalent, but in different time spans. This setup allows distinguishing between rate and volume as a cause for the climatic change observed.

While the mechanisms we are discussing are likely to be valid in any coupled climate model, one should not forget that the results of the present study are performed with a single climate model. The response to freshwater forcings as discussed in this study is most likely different for each model, as the sensitivity to freshwater input scenarios varies considerably between models. In its present version, the LOVECLIM model needs about $0.2 \mathrm{~Sv}$ of freshwater 
Table 1 Experiments performed

\begin{tabular}{llll}
\hline $\begin{array}{l}\text { Experiment } \\
\text { (years) }\end{array}$ & $\begin{array}{l}\text { Max. flux } \\
(\mathrm{cSv})\end{array}$ & $\begin{array}{l}\text { Pulse duration } \\
\text { (years) }\end{array}$ & $\begin{array}{l}\text { e.s.l Equivalent } \\
(\mathrm{m})\end{array}$ \\
\hline $10 \mathrm{cSV}(100)$ & 10 & 100 & 0.87 \\
$30 \mathrm{cSV}(100)$ & 30 & 100 & 2.62 \\
$15 \mathrm{cSV}(200)$ & 15 & 200 & 2.62 \\
$20 \mathrm{cSV}(200)$ & 20 & 200 & 4.37 \\
$30 \mathrm{cSV}(200)$ & 30 & 200 & 5.24 \\
$15 \mathrm{cSV}(400)$ & 15 & 400 & 5.24 \\
$25 \mathrm{cSV}(200)$ & 25 & 200 & 5.46
\end{tabular}

Max. fux is the maximum freshwater flux added in cSv; e.s.l. stands for "eustatic sea level"

added to the North Atlantic to achieve a full shutdown of the North Atlantic Deep Water (NADW) formation (Roche et al. 2007; Weber et al. 2007) under LGM conditions. Results have to be interpreted relatively to this specific threshold.

\subsection{Outline of the basic LGM state}

The LGM state used in this study has been obtained by integrating the LOVECLIM model under constant LGM boundary conditions to equilibrium, as described in detail by Roche et al. (2007). Deep water formation in the model takes place at two locations in the Northern Hemisphere: a main one (in terms of amount of deep water produced) south of Iceland and a secondary one (producing the deepest waters) in the Nordic Seas. This feature was is consistent with proxy-data evidence (Labeyrie et al. 1992; Oppo and Lehman 1993; Dokken and Jansen 1999; Meland et al. 2008) and is crucial to assess the role of spatially explicit freshwater forcing. Indeed it allows to have more intermediate states than the classical on and off (defined as in (Ganopolski and Rahmstorf 2001)) by preventing (or reducing) convection in either of the sites or in both at the same time.

\section{Response of NADW export to freshwater forcing}

Adding freshwater to the surface ocean lessens its density, eventually inhibiting the deep waters to form. Therefore, an anticipated response of the ocean to freshwater forcing is a reduction (or a cessation) of deep water formation in areas close to the applied freshwater flux. This is especially true for the Atlantic Meridional Overturning Circulation (AMOC) when freshwater is applied close to or over the North Atlantic. When the forcing ceases the NADW export will return to its initial value if the ocean circulation has only one stable mode. The time needed to reach the initial

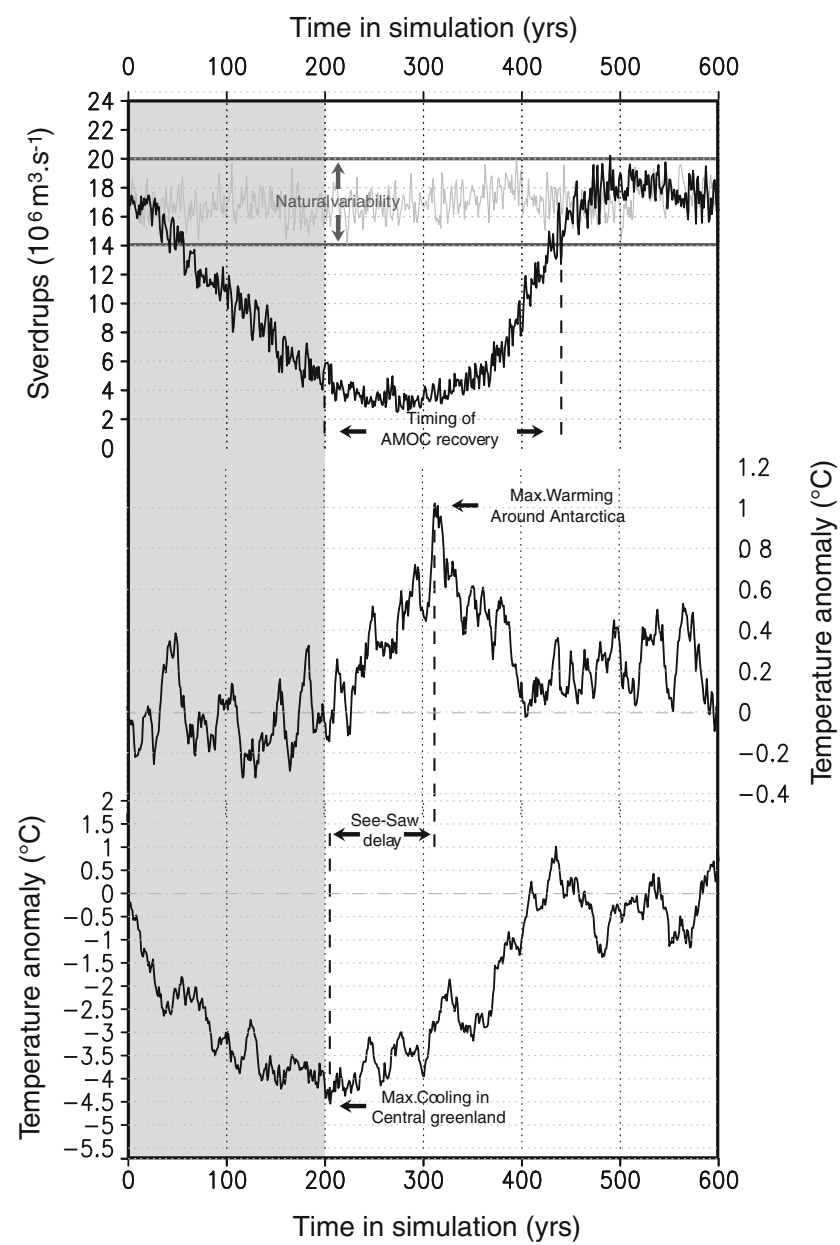

Fig. 2 Time evolution of overturning, Greenland and CircumAntartic temperature in experiment $20 \mathrm{cSV}$ (200 years), in zone FISM. From top to bottom: NADW export to the Southern Ocean (black line) throughout the experiment compared to the control LGM experiment (grey line). Below is the Circum-Antarctic temperature anomaly with respect to the beginning of the experiment (black line). Last is the Greenland temperature anomaly with respect to the beginning of the experiment

value after the end of the forcing will then depend on how the deep convection sites has been affected. In the following sections, we analyse the global responses of all the scenarios integrated in the present study. To illustrate the mechanisms which we refer to, Fig. 2 presents times series from experiment $20 \mathrm{cSv}$ (200 years) with freshwater input in FISM.

\subsection{Relative decrease in NADW export}

Figure 3 shows the effect of each scenario on the NADW export to the Southern Ocean, relative to the start of the experiment. The NADW export to the Southern Ocean is defined here as the maximum of the Atlantic overturning streamfunction at $20^{\circ} \mathrm{S}$. 


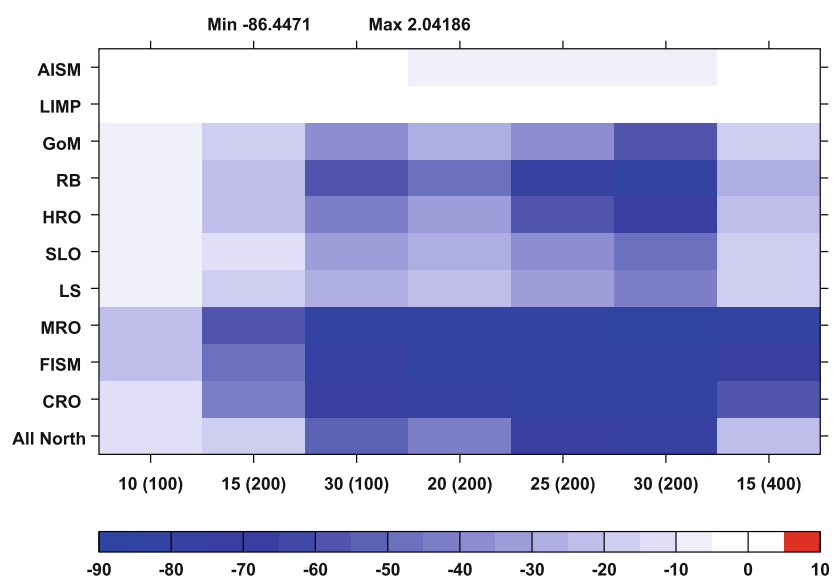

Fig. 3 Maximum relative change in North Atlantic Deep Water export to the Southern Ocean. The $x$-axis depicts the parameters for each simulation forcing scenarios, units in $\mathrm{cSv}$ (years). The $y$-axis show the zones by acronym. Colorscale is in percent

Three groups of zones can be defined with respect to the relative decrease of NADW export to the Southern Ocean. The group of zones that has the largest impact (more than $70 \%$ reduction in NADW export in the most extreme cases) is constituted of FISM, RB, the Arctic outlet (MRO) and CRO. FISM, RB and CRO are dynamically close to the zones of deep water formation: FISM and CRO are upstream of the Nordic Seas convection area (cf. Fig. 1) and RB is situated upstream to the south of Iceland convection area. By "upstream" we mean that the upper ocean circulation induces a direct advection from the zone where the freshwater forcing is added to an intially unperturbed convection zone. This direct link enhances the sensitivity of the particular convection zone preventing mixing of the anomalous freshwater signal on the way. Forcing FISM or CRO yields almost the same response as RB in terms of NADW export reduction, even if the freshwater affects a different convection area (cf. Fig. 4). The Arctic forcing (MRO) is also very effective in reducing the NADW export to the Southern Ocean but the mechanism is somewhat different. The advection of the anomalous signal is achieved through the mediation of sea-ice (cf. Fig. 5), also preventing mixing on the way.

The second group of zones is constituted by the Eastern American coast Outlets, the Gulf of Mexico (GoM), the Labrador Sea (LS). Applying a freshwater forcing in each of these areas results in a substantial reduction of the NADW export (up to about 40-50), but with little or no effect for small magnitude pulses. Dynamically, they are more remote from the convection areas and freshwater introduced in the Atlantic outlets (SLO, HRO, GoM) undergo some mixing before reaching them.

The third group comprises the Pacific (LIMP) and the Antarctic (AISM) zones. Adding freshwater to these zones

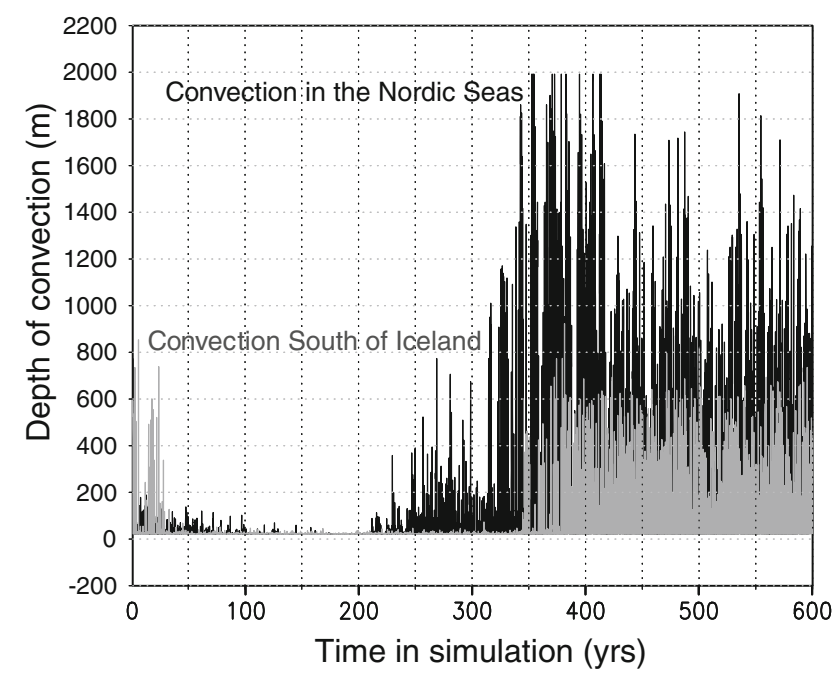

Fig. 4 Depth of convection in the two main deep water locations in experiment CRO with flux $20 \mathrm{cSv}$ (200 years). It illustrates the fact that forcing a region close to a deep water formation zone (in this case $\mathrm{CRO}$, close to the Nordic Seas convection site, black line) first affects this site, preventing shutdown for some time in the other deep convection site (here the south of Iceland convection site, grey line). In the case of the experiment shown, the delay is of about 35 years. The reverse is true for the recovery

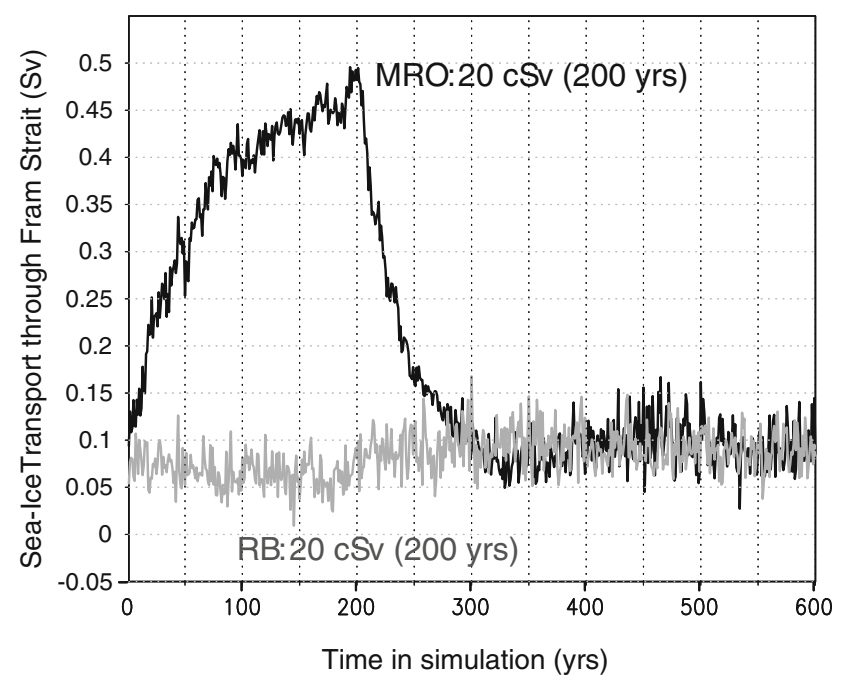

Fig. 5 Sea-ice transport through Fram Strait for experiments MRO (black line) and RB (grey line) both with a scenario $20 \mathrm{cSv}(200$ years). It illustrates that adding freshwater in the Arctic (MRO) enhances considerably the sea-ice formation in the Arctic and that the sea-ice is transported southward as shown by the transport through Fram strait

has a very limited impact on the NADW export. The absence of response when freshwater is added around Antarctica is linked to the spreading of the anomaly around the continent as defined in our set-up but also to the oceanic currents which efficiently mix the forcing. The addition of freshwater to the Pacific has no significant impact on the NADW export. As we are using the LGM boundary 
conditions, the Bering Strait is closed, and hence there is no direct influence of the north Pacific to the north Atlantic through the ocean. We will show later on that the addition of freshwater to the Pacific has nonetheless a strong climatic impact in regions around the North Atlantic.

Several simulations integrated here have similar total freshwater contributions: namely $15 \mathrm{cSv}$ (200 years) \& 30 cSv (100 years) or $30 \mathrm{cSv}$ (200 years) \& $15 \mathrm{cSv}$ (400 years). Conversely, several experiments have the same freshwater input rate but different total freshwater input (e.g. $15 \mathrm{cSv}$ (200 years) \& $15 \mathrm{cSv}$ (400 years)), allowing us to investigate the relative role of the rate of freshening versus total amount of freshwater. Figure 3 clearly shows that the most important effect is the maximum flux of freshwater added to the ocean, whereas the total freshwater amount has only a second-order effect. This is consistent with the numerous studies investigating the so-called hysteresis behaviour of the coupled atmosphere-ocean system, in which applying a certain amount of freshwater in quasiequilibrium will not lead to a disruption of the NADW production as long as a threshold is not crossed (Ganopolski et al. 1998; Rahmstorf et al. 2005). In our model, the most severe changes are occurring for fluxes above 20 $\mathrm{cSv}$, suggesting that the threshold is nearby this value. It is also consistent with previous studies involving an earlier version of the same model (Weber et al. 2007). If the freshwater threshold is not crossed (e.g. $15 \mathrm{cSv}$ (200 years) $\& 15 \mathrm{cSv}$ (400 years)), doubling the duration of the same flux diminishes NADW export by $\simeq 10-15 \%$, consistently over the different simulations.

\subsection{Recovering NADW export: relative timing}

Once the ocean circulation has been perturbed by a given freshwater forcing, it recovers if it has only one stable state, as it is the case in our model. Figure 6 shows the time needed for the North Atlantic deep water formation to recover after the end of each pulse. We define this time as the first year for which the value of the export of North Atlantic Deep Water to the Southern Atlantic returns within the one sigma variability of the export in the control run, relative to the last year of the freshwater perturbation. Figure 2, top, shows an example of the definition of the time needed for the NADW deep water export to recover to its intial value for experiment FISM $20 \mathrm{cSv}$ (200 years). This definition has the advantage of showing the true timelag induced by the freshwater pulse to the ocean. There are examples in palaeoclimate where a climate signal is lagging the freshwater pulse entering the ocean considered to be the cause of the event (e.g. the Younger-Dryas cold event during the last glacial termination (Tarasov and Peltier 2005)). Considering the real lag between the pulse and the end of the oceanic perturbation will facilitate

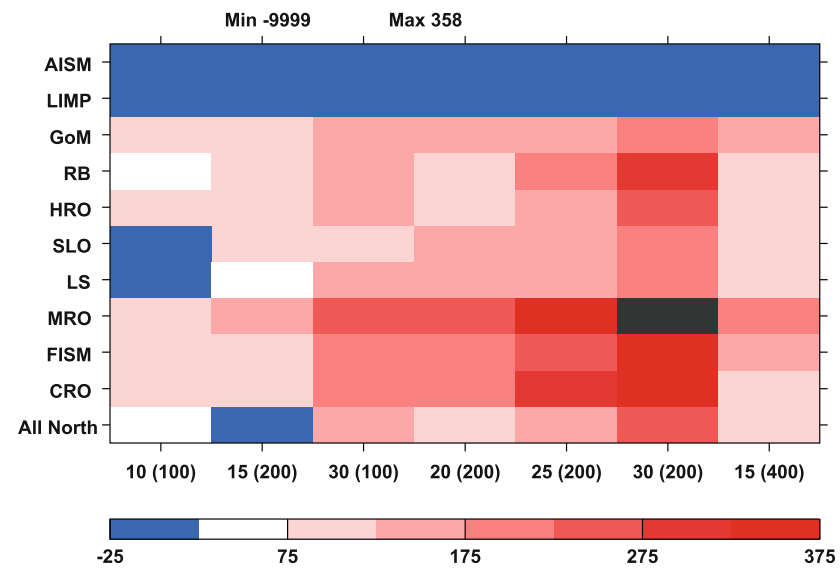

Fig. 6 Maximum time needed for the recovery of the Atlantic Meridional Overturning Circulation. The recovery (in years) is considered to be achieved when the strength of the North Atlantic export to the Southern Hemisphere returns within a one-sigma band defined from the control run. Axes are identical as in Fig. 3. The zone in dark grey never recovers within the simulation length (recovery time greater than 400 years)

data-model comparisons for such periods in future studies. Our experiments exhibit large differences in timing of recovery, ranging from a small negative duration (when the recovery is achieved before the end of the applied pulse) to up to more than four centuries. Of particular interest are the large differences between the different zones for the same freshwater pulse. Three different classes can be defined, leaving the Pacific (LIMP) and the Antarctic (AISM) aside.

The first class consists of zones with relatively short recovery time for experiments with a strong NADW export perturbation (e.g. about a century for the experiments with scenario $20 \mathrm{cSv}$ (200 years). This class contains all zones which are remote from the deep convection zones and/or affect easily only one site. This is the case for GoM, RB, the East American coast Outlets (EAO) and LS. They mainly affect the convection zone south of Iceland, but only the strongest pulses are able to reach the Nordic Seas, as for the RB in experiment $30 \mathrm{cSv}$ (200 years), where the recovery time increases to three centuries. The second group comprises the Western European coast sites (FISM $\&$ CRO) which can easily affect convection but also the sea-ice cover in the Nordic Seas. As for the previous class, the strongest pulses are able to affect the convection site south of Iceland (e.g. $30 \mathrm{cSv}$ (200 years) or $25 \mathrm{cSv}$ (200 years), partly via sea-ice transport through the Fram Strait. The last class is constituted by the MRO (Arctic) forcing alone. Its timing of recovery for a given pulse is systematically longer than any of the other zones (experiment $30 \mathrm{cSv}$ (200 years) does not recover in 400 years). This can be explained by direct export of freshwater via surface waters and sea-ice to the convection site in the Nordic Seas (simple downstream advection) but also to the south of 
Iceland convection site through Fram Strait (cf. Fig. 5). MRO is the only zone considered here which is directly linked to both deep convection sites and has therefore the highest potential for modifying deep convection.

As a conclusion to a first order, the decrease of NADW export does respond in line with expectations, namely that forcing the ocean in an area close to a deep convection site may have a important impact, while applying the forcing in geographically more remote areas-or areas not connected through simple ocean transport to the previous ones-have a more limited impact. We have also shown that our model is most sensitive to the maximum flux of freshwater entering the ocean and only to a lesser extent to the total amount of freshwater added. From simple considerations on the timing of recovery, we can also conclude that in order to increase the timing needed for recovering the full AMOC strength after a freshwater perturbation, one needs to perturb convection in all northern convection sites. If only one of our two convection sites is perturbed, the second one acts as a flush and tends to convect the negative buoyancy anomaly in the deep ocean. As the perturbation ceases, the anomaly is removed efficiently from the surface ocean, enabling a fast recovery to the pre-perturbed mode of deep convection. An example of this mechanism is provided by the CRO experiments . Experiment $15 \mathrm{cSv}$ (200 years) maintains deep convection south of Iceland (not shown) enabling a fast recovery (less than a century) of the NADW export to the Southern Hemisphere. Experiment $25 \mathrm{cSv}$ (200 years) on the other hand shuts down deep convection in both sites, delaying the recovery of the NADW export by up to two centuries.

\section{Sea-ice distribution under freshwater forcing}

Three main processes are involved in the link between freshwater forcing of the surface ocean and the sea-ice distribution. First, adding freshwater to the surface ocean diminishes the salinity of the surface water where the water is added, hence favouring the freezing of water at lower salinities. Second, adding freshwater to the surface ocean favours the establishment of a freshwater lid (corresponding to the first layer of the ocean in our model), isolating the upper layers from the underlying ocean. This helps to cool down the surface waters, and hence to produce sea-ice. The third process is a negative feedback: the formation of sea-ice helps to increase convection via salt rejection, as sea-ice is almost fresh water (brine rejection).

Figure 7 shows the relative changes of the maximum sea-ice extent in the Northern Hemisphere, while Fig. 8 shows the modifications in the seasonal range (winter minus summer) extent of Northern Hemisphere sea-ice.

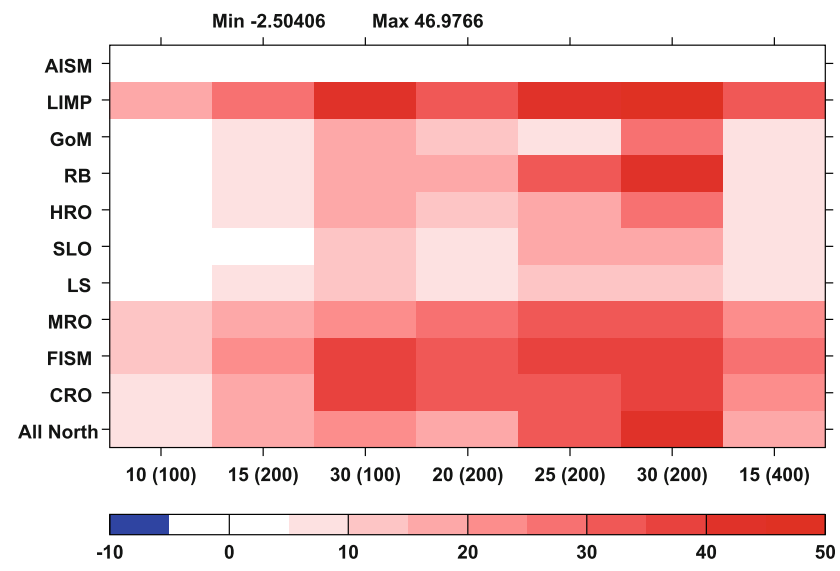

Fig. 7 Relative change (percent) in the maximum extent of Northern Hemisphere sea-ice. Axes are identical as in Fig. 3. The sea-ice extent is taken as the sea-ice concentration in each grid cell multiplied by the area of the grid cell

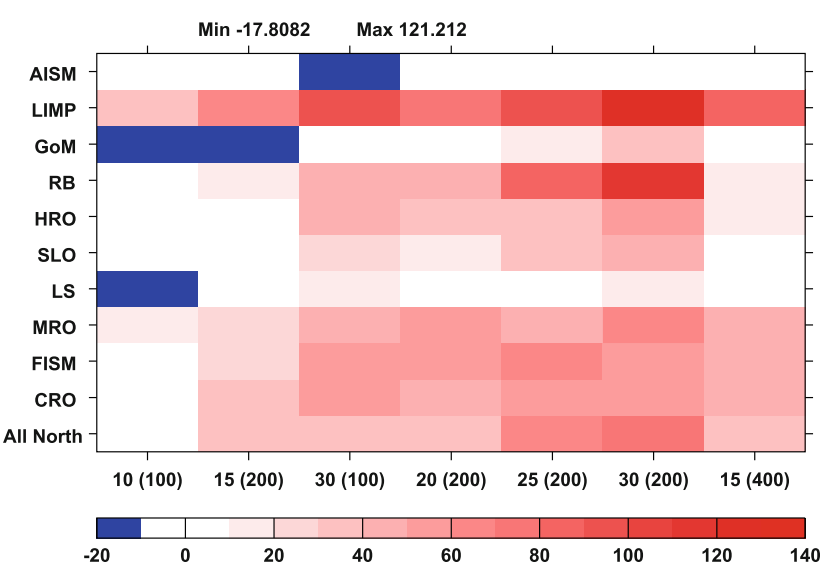

Fig. 8 Relative change (percent) in the seasonal amplitude of Northern Hemisphere sea-ice. Axes are identical as in Fig. 3

The winter sea-ice extent (10 years running average) in the Northern Hemisphere can be increased by as much as $47 \%$ in the most extreme experiments. Figure 7 shows that there is a large variability within the zones to a given amount of freshwater forcing in the response of maximum sea-ice extent. Zones which respond most strongly to the additional freshwater are those close to the edge of the modelled LGM maximum sea-ice extent: CRO, MRO and to a lesser extent FISM, where some sea-ice already exists, but as a relatively discontinuous cover (see (Roche et al. 2007)). The case of the Pacific Ocean freshwater forcing is similar: there is no winter sea-ice coverage in the Pacific in the control where we add the freshwater flux but extensive winter sea-ice when the freshwater is applied. Therefore the relative increase of the winter sea-ice coverage due to Pacific freshwater forcing is the largest of all zones. This has a strong impact on temperatures, as will be discussed below. A second group of zones has a winter sea-ice extent 
that responds moderately to the imposed freshwater forcing: it is constituted of EAO and the Labrador Sea. Their response is however quite different: the former two zones (HRO \& SLO) are situated in a warmer region preventing the formation of a large winter sea-ice extent on site, whilst the opposite is true for the Labrador Sea, which is already covered by sea-ice all year round. This can be inferred from Fig. 8, as there are mainly no seasonal changes in seaice extent in the Labrador Sea. The effect of adding freshwater in this latter case is therefore to increase in situ sea-ice thickness and to facilitate the formation of sea-ice from the limit of the control winter sea-ice. From Fig. 7, one can infer that putting freshwater in the SLO is less effective than adding it in the HRO in terms of winter seaice extent. These results might seem counter-intuitive as the SLO is close to the sea-ice edge in the control experiment, whereas the HRO is more remote. However, if adding freshwater to the SLO helps formation of sea-ice on site and in the neighbourhood, adding freshwater to the HRO helps decrease the salinity of the upper branch of the AMOC and ultimately facilitates the formation of more winter sea-ice along the European continent. As we already discussed, the response of the system to the input of freshwater flux in the CRO and FISM zones are strong, compared to the response to a perturbation applied in HRO, which is comparable to a weak perturbation applied in FISM. Indeed, in the latter case, the signal needs to be advected along the North Atlantic Drift. As expected, there is not much signal in the Northern Hemisphere when freshwater is added around Antarctica.

Figure 8 shows that the sea-ice seasonal range response is different from the winter extent one. We define here the seasonal range as being the difference between the winter maximum extent and the summer minimum extent. The marked Pacific (LIMP) response indicates a strong increase in winter sea-ice but not much change in summer. Response to perturbations in northern and northwestern regions (MRO, FISM and CRO) are much smaller in terms of seasonal amplitude than winter extent. This indicates that the summer sea-ice extent increases as much as the winter extent in the latter case while it is barely modified in the LIMP case. In particular, the experiments involving the Labrador Sea (LS) have an very similar seasonal range while they do show some increase in the winter sea-ice extent in response to the stronger meltwater forcing. The $\mathrm{RB}$ region is more comparable to the Pacific while EAO are showing an intermediate seasonal response, more comparable to CRO and FISM. We can therefore infer that those cases showing a strong seasonnal increase and a strong winter sea-ice increase (LIMP, RB) correspond to forcing regions where not much sea-ice is present in the control LGM simulation neither in summer nor in winter. The addition of a freshwater flux helps to form sea-ice
Fig. 9 Combined Surface Air Temperature anomalies (in ${ }^{\circ} \mathrm{C}$ ) for each freshwater input region, at time of maximum cooling in Greenland. See text for details on the construction of the anomalies maps. From top to bottom and left to right, zones are: Fennoscandian Ice Sheet Margin (FISM), Ruddiman Belt $(R B)$, Labrador Sea $(L S)$, Saint Lawrence Outlet ( $S L O)$, Hudson River Outlet (HRO), Gulf of Mexico $(G o M)$, MacKenzie River Outlet $(M R O)$, Channel River Outlet $(C R O)$, Laurentide Ice Sheet Margin on the Pacific side (LIMP) and Antarctic Ice Sheet Margin (AISM)

during winter but is not sufficient to modify the surface ocean throughout the year, increasing the seasonality of the sea-ice extent. In contrast the LS region is covered during both winter and summer in the LGM control run (Roche et al. 2007), the addition of freshwater has therefore little effect on the sea-ice cover locally, but increases it both in winter and summer at the edge of the LGM control cover. MRO, CRO and FISM experiments present a considerable increase in winter sea-ice cover (primarily in the Nordic Seas and in the northern North Atlantic) but do not show such an increase in summer sea-ice. The seasonal amplitude is therefore substantially increased. These different dynamics are important to better understand the seasonal and annual evolution of the climate during potential meltwater events.

\section{Temperature response}

Our aim in analysing the temperature response for each freshwater input zone is to characterise the local temperature response so as to examine the possibility of fingerprinting the freshwater input location. Indeed forcing in the north Pacific is unlikely to yield a comparable temperature response as applying it to Antarctica or to the Arctic: we will therefore try to characterize each input zone by its own temperature response.

We choose to analyse the response of our experiments from an ice-core perspective: we compare the average temperature anomaly in the Northern Hemisphere of the different experiments performed for a particular freshwater forcing zone, at time of the maximum cooling in Central Greenland (Fig. 9). This results in a Greenland-centric view, consistent with many paleodata analyses in which Greenland ice-cores are used as a reference. The maps on Fig. 9 therefore show, for each of the previously defined zones in which freshwater perturbations are applied the resulting temperature anomaly at time of maximum cooling in Central Greenland. It should be noted that the maximum/ minimum temperature for a specific region can be different than that shown on these maps if the temperature response in a region is not synchronous with Central Greenland (as shown on Fig. 2). The method employed guarantees the consistency of the temperature anomaly pattern amongst the different experiments, but not the absolute values. 

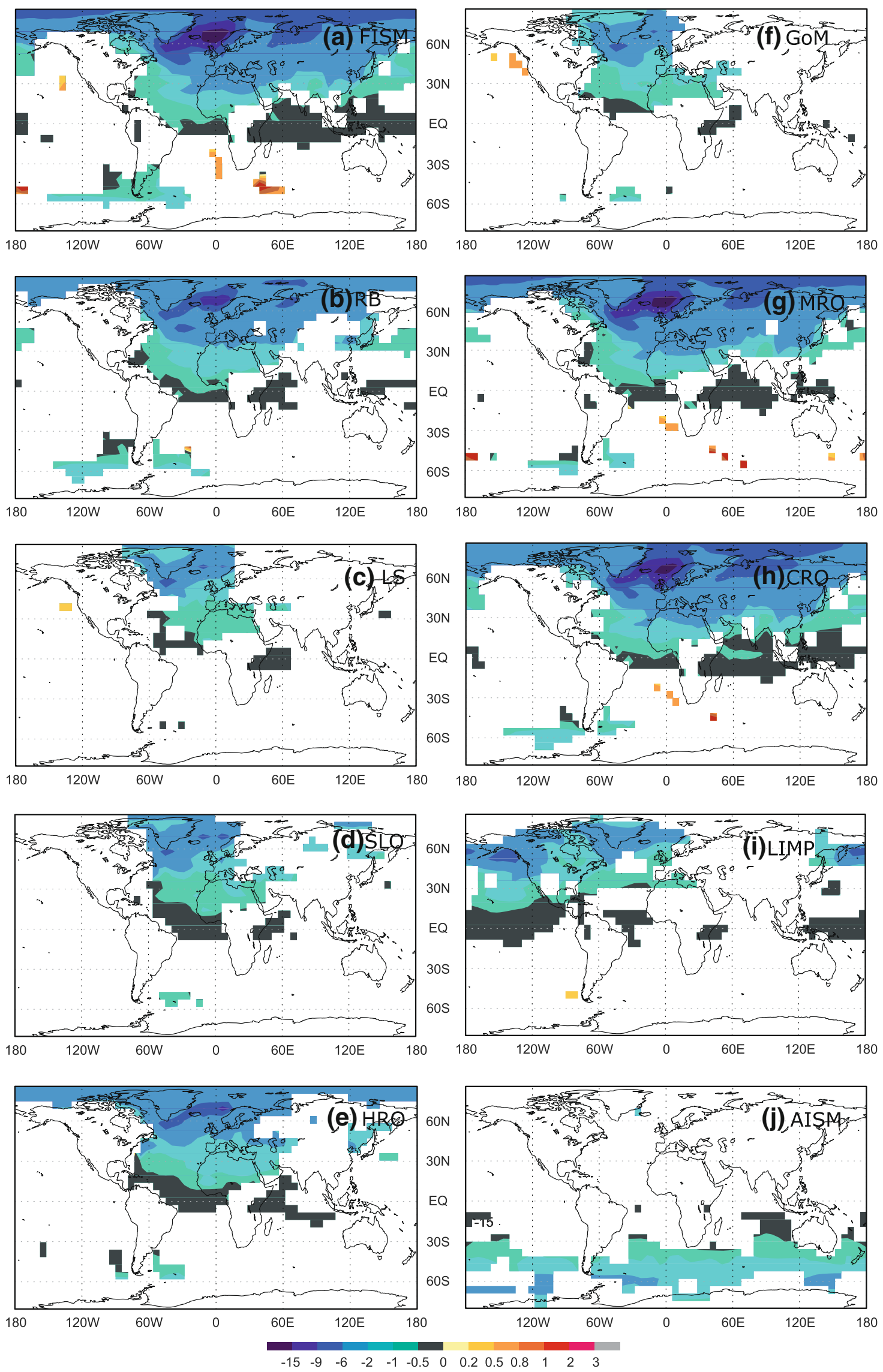


\subsection{Method employed}

To compute a temperature anomaly pattern from the simulations we followed these steps, based on the approach developped by Wiersma (2008):

- Compute the 10-years moving average of the monthly mean surface atmospheric temperature (SAT) fields in order to filter out sub-decadal variability. The use of 10 -years moving average is a subjective choice, but is reasonable in order to obtain a climatic response on the order a few decades to centuries, as expected here.

- Find the coldest decade in Central Greenland using a $t$ test with unequal sample sizes and having possibly two unequal variances. The $95 \%$ significance level is used for the $t$ test.

- Extract global maps of the significant temperature anomaly of the previously determined decade with respect to the control climate with the same $t$ test at a 95\% level of significance. At that point we are left with one map per experiment. As we want to investigate the common pattern found in every experiment for a specific zone, we add the following step:

- For each zones, we combine the seven maps obtained from the seven experimental settings (cf. Table 1) in one map by averaging the statistically significant temperature anomaly in each location when the temperature anomaly have the same sign (i.e. cooling or warming) in all experiments. When temperature anomalies differ in sign, no values are plotted on the final map, to ensure the physical consistency of the plotted temperature.

\subsection{Geographical patterns in the temperature response}

The geographical pattern of the significant temperature anomalies at time of coldest Greenland climate can be grouped in three classes (see Fig. 9): the "North Atlantic" class, the "Northern Hemisphere" class and a "heterogeneous" class including previously unclassified experiments. The North Atlantic group comprises LS , GoM and SLO (Fig. 9c, d and f) whose temperature anomalies are centred on the North Atlantic with only moderate extension to the nearby continents (apart from Greenland). As discussed before, applying a perturbation in these three zones mainly affects the convection zone south of Iceland, thereby influencing the north Atlantic climate. However, the deep convection zone in the Nordic Seas remains active, climate conditions are not so much modified in the Arctic and nearby regions. Western Europe and northwest Africa experience moderate cooling (by $1-2^{\circ} \mathrm{C}$ ), through downwind atmospheric connection. The Northern Hemisphere group is constituted of FISM, MRO, CRO and, though slightly different, of RB \& HRO (Fig. 9 a, b, e, g and h).
Their temperature anomalies covers almost the entire Northern Hemisphere with the notable exception of North America and the East Pacific. The maximum temperature anomaly is in the Nordic Seas with at least $10^{\circ} \mathrm{C}$ cooling and Eurasia experiences a cooling of $2-5^{\circ} \mathrm{C}$. Within the group, FISM, MRO \& CRO are showing a statistically significant warming in several areas around $30^{\circ} \mathrm{S}$ while RB \& HRO do not significantly warm up there. This is in line with the obtained reduction of the AMOC as discussed earlier: the reduction in the export of NADW to the Southern Hemisphere is greater in FISM, MRO \& CRO than in any other zone. From a mechanistic point of view, the more the AMOC is reduced, the greater the reduction in oceanic heat transport to the north Atlantic region and therefore the more chances to warm up the Southern Hemisphere. The early small warming in FISM, MRO \& CRO shows that if the perturbation of the NADW is strong enough, the southern warming occurs earlier on while the maximum warming is still later on (see hereafter). In particular, the deep convection in the Nordic Sea is less affected in RB \& HRO, both sites being more remote geographically and some of the freshwater being carried away in the subtropical gyre. An additional feature is the significant cooling of ca. $2^{\circ} \mathrm{C}$ obtained around the tip of South America, both in the Southern Atlantic Ocean and in the South-eastern Pacific. It is in opposition with the classical Southern Ocean warming during AMOC reduction, and is present in all simulations of this group. The surface cooling is due to a coupled atmosphere-ocean interaction. The lower AMOC strength reduces the ocean heat transport to the Northern Hemisphere and therefore tends to store more heat in the Southern Hemisphere. This enhanced heat content increases the geopotential height in the atmosphere in the eastern South Atlantic and southern Indian Oceans modifying the atmospheric wave patterns around Antarctica (Fig. 10). This in turn favors a more cyclonic atmospheric circulation over the western South Atlantic Ocean (around $50^{\circ} \mathrm{S}$ ). The changes in the atmospheric winds are mirrored in the ocean with less northward advection of heat promoting warmer temperatures in the eastern South Atlantic and in the southern Indian Ocean (Fig. 10). In the western South Atlantic Ocean, the more cyclonic conditions of the atmosphere are mirrored by a enhanced clockwise circulation, bringing colder waters to the North, along the coast of Argentina. This situation reinforces the cyclonic circulation of the atmosphere, stabilizing these anomalous conditions. A consequence of these modifications is also the increased transport through the Drake Passage. The same broad pattern is obtained when one looks later in the simulation (cf. Fig. 11). The reinforcement of the atmospheric anomaly by the oceanic circulation along a coast is not unlike the result found by Saenko et al. (2007) with a GCM though being of opposite sign. They found a self-sustained 

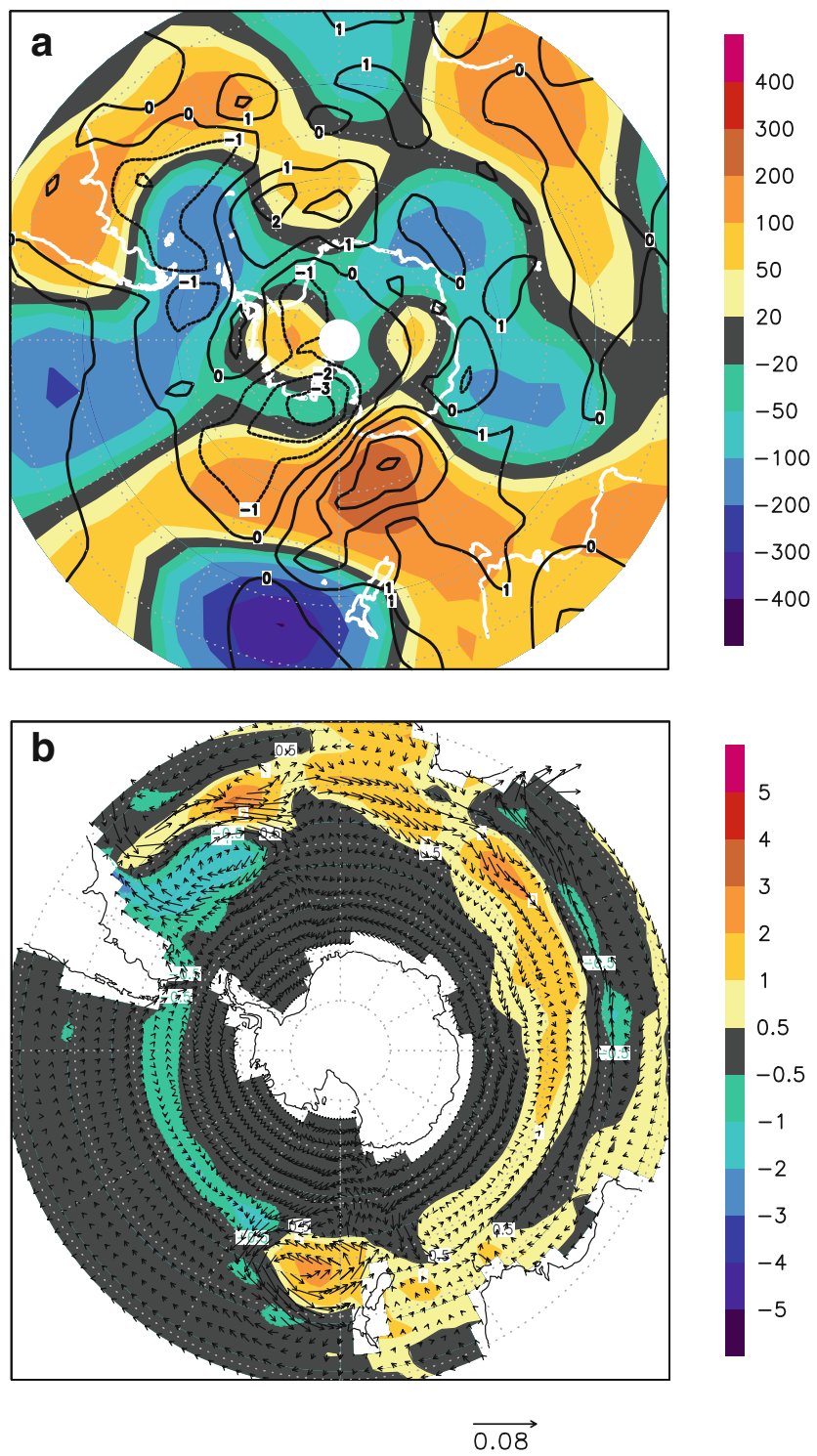

Fig. 10 Atmospheric and oceanic Southern Hemisphere changes in experiment FISM $30 \mathrm{cSv}$ (200 years). Panel a shows the anomaly of geopotential height at $850 \mathrm{hPa}$ (colorscale in meters), superimposed contours show the SAT anomaly (in ${ }^{\circ} \mathrm{C}$ ). For both variables, the zonal mean has been subtracted. Panel b shows comparable anomalies for the ocean with arrows (scaling arrow of $0.08 \mathrm{~m}$ per second shown) showing the oceanic currents average over $0-100 \mathrm{~m}$ depth superimposed over the sea surface temperature anomaly (colorscale in ${ }^{\circ} \mathrm{C}$ )

atmosphere-ocean warming along the North American coast as direct response of North Hemisphere freshwater forcing, while we find an atmosphere-ocean cold anomaly in the Southern Hemisphere along the coast of Argentina as a response of reduced AMOC. Our results show that the details of the response of a model to a precisely defined forcing are crucial to understand in which respect one is able to reproduce the past climate dynamics.

The third group contains the other experiments: LIMP and AISM (Fig. 9 f, i and j) whose temperature responses are different from the others. Adding freshwater to the LIMP zone leads to a strong local response, driven by seaice increase. The cooling obtained (more than $6^{\circ} \mathrm{C}$ ) is significant and the anomaly extends almost hemispherically, both downwind and upwind from the LIMP zone, indicating a regional response on the whole North Pacific region. The Arctic is not significantly affected while the North Atlantic cools down by as much as $5^{\circ} \mathrm{C}$. This latter difference is due to the absence of a NADW weakening: the LIMP forcing primarily affects the sea-ice cover and results in a regional temperature response.

Comparing LIMP with the Northern Hemisphere group shows one additional interesting feature: considering the Northern Hemisphere north of $30^{\circ} \mathrm{N}$, in both ensembles there is a region with no significant changes in temperature, $70-80^{\circ}$ in longitude westward from the anomaly (that is in the upwind direction). The analysis of the geopotential height at 850 hpa (Fig. 12) shows that there is a change in long waves patterns in the atmosphere. The cold temperature anomaly generated above the forcing region provokes a low in the geopotential height and a more cyclonic circulation type in the atmosphere. The Northern Hemisphere atmospheric circulation responds with a wave pattern $(n=1)$, generating a high in the geopotential height above Eastern Russia and the North Pacific for the Northern Hemisphere group. The response is mainly barotopic except over the ice-sheets. This wave pattern response to the freshwater forcing in the North Atlantic forces a more anticyclonic circulation pattern in the eastern North Pacific, promoting the advection of warmer air from the sub-tropic, compensating the cold anomaly advected by the main atmospheric circulation from the North Atlantic region. The response is similar for the LIMP experiment. This feature is to be present in other models (e.g. Stouffer et al. (2006, their Fig. 14), though not to the extent of producing a warming, but more a reduced cooling in an ensemble of AOGCMs as a response to Northern Hemisphere hosing.

The AISM forcing produces a hemispheric cooling around Antarctica at the time of maximum cooling in Greenland, consistent with our zonally homogeneous forcing. The coldest anomaly is situated above the forcing region where the formation of sea-ice is facilitated. Interestingly, there is no evidence for antiphased warming/cooling between the Northern/Southern Hemisphere. This response is consistent to what is found in other coupled atmosphere ocean models (Seidov et al. 2005; Stouffer et al. 2007) showing that the see-saw mechanism is not a symmetrical feature: forcing the northern Atlantic with a freshwater flux might lead to a warming in the Southern Hemisphere whereas forcing the Southern Ocean with freshwater does not lead to significant warming in the northern Atlantic. This points to the non-symmetrical nature of the Atlantic MOC which transports heat from 

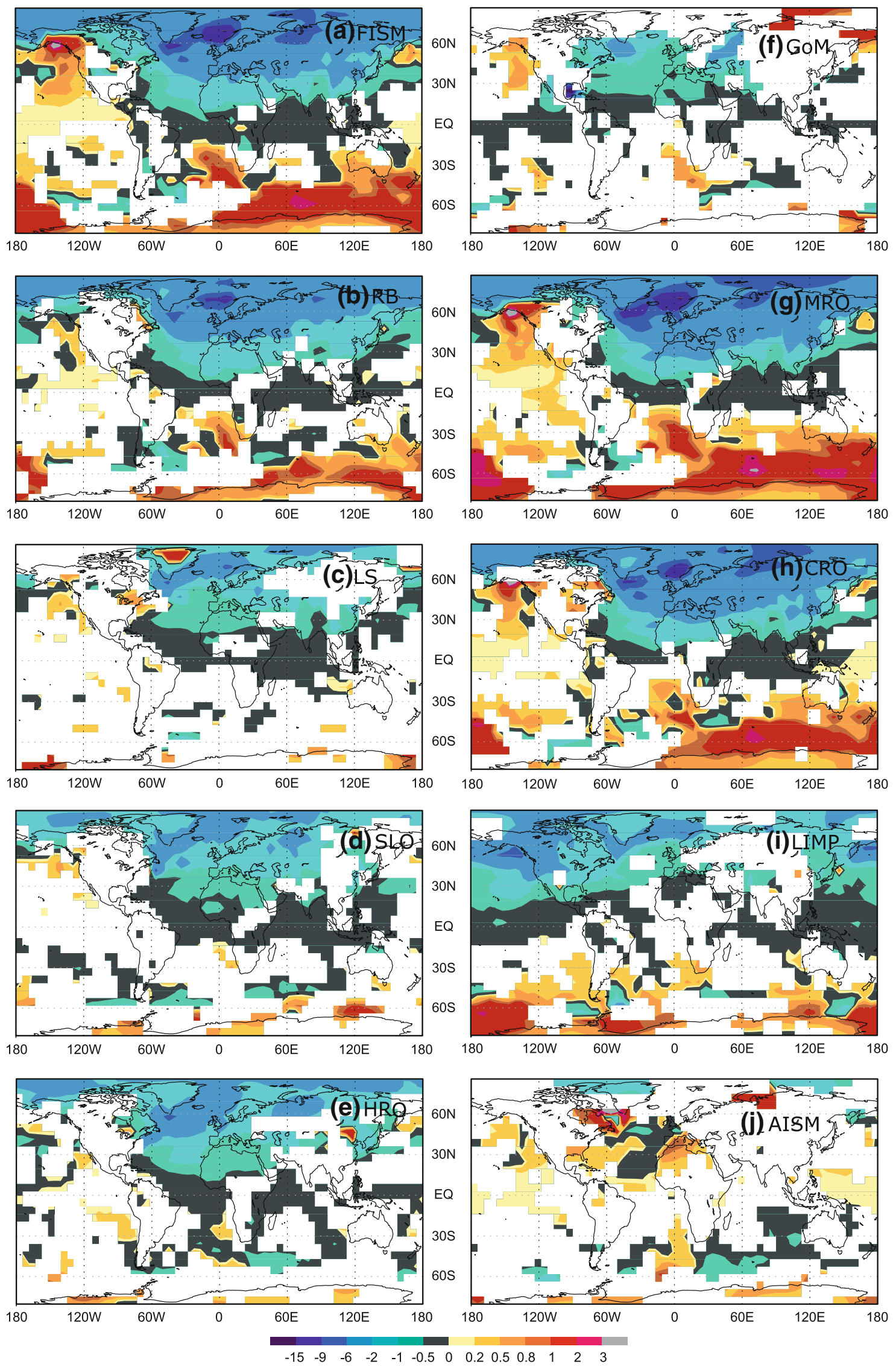
4 Fig. 11 Combined surface air temperature anomalies (in ${ }^{\circ} \mathrm{C}$ ) for each freshwater input region, at time of maximum Southern Ocean warming. See text for details on the construction of the anomalies maps. From top to bottom and left to right, zones are: Fennoscandian Ice Sheet Margin (FISM), Ruddiman Belt $(R B)$, Labrador Sea $(L S)$, Saint Lawrence Outlet ( $S L O)$, Hudson River Outlet (HRO), Gulf of Mexico $(G o M)$, MacKenzie River Outlet $(M R O)$, Channel River Outlet $(C R O)$, Laurentide Ice Sheet Margin on the Pacific side (LIMP) and Antarctic Ice Sheet Margin (AISM)

the Southern Ocean to the North Atlantic. This asymmetry is also due to the Earth's geometry as is discussed in detail by Stouffer et al. (2007): the Southern Ocean allows fast spreading of the surface salinity anomaly whereas the North Atlantic, being a more closed basin, retains the negative buoyancy forcing. One can also note that our results confirm that the sign of the NADW export to the Southern Hemisphere depends on the initial state of the THC. Indeed, in our study the NADW export slightly weakens due to the AISM freshwater input in accordance with Stouffer et al. (2007) as opposed to the results of Weaver et al. (2003). Stouffer et al. (2007) attributed this difference to the initial state of the Atlantic THC which would weaken if the experiment started from an "on" state (and vice-versa); our results confirm their analysis. It should be additionally noted that maps shown on Fig. 9 are not for the time of coldest period in the Southern Ocean, as is discussed in details in the next section.

\subsection{Bipolar see-saw}

Here, "bipolar see-saw" means the warming occurring in the Southern Hemisphere due to diminished northward heat

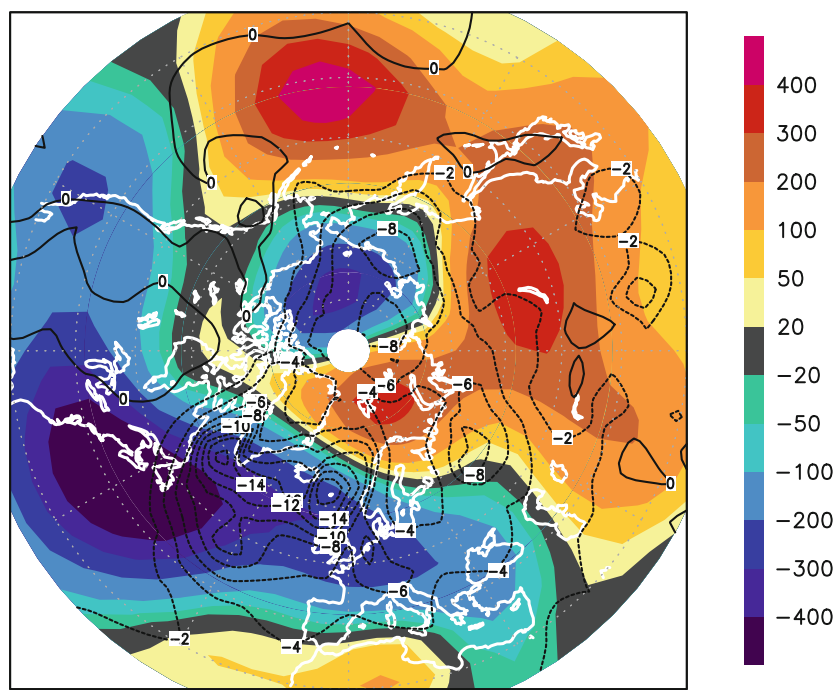

Fig. 12 Atmospheric Northern Hemisphere changes in experiment FISM $30 \mathrm{cSv}$ (200 years). Figure shows the anomaly of geopotential height at $850 \mathrm{hPa}$ (colorscale in meters), superimposed contours show the SAT anomaly (in ${ }^{\circ} \mathrm{C}$ ). For both variables, the zonal mean has been subtracted transport by the Atlantic Ocean when the THC is perturbed. This mechanism was shown to play an important role when perturbing the northern Atlantic Ocean by freshwater fluxes (Crowley 1992; Seidov et al. 1998).

Figure 9 shows that there is very little warming in any of the experiments at time of coldest Greenland temperatures. This is not surprising for several reasons: (a) ice-core evidence shows that the maximum warming in the Southern Hemisphere occurs later than the coldest period in Greenland (Petit et al. 1999; EPICA community members 2004) (b) modelling studies using schematic freshwater fluxes scenarios indeed show such a temporal shift (e.g. Ganopolski and Rahmstorf (2001); Seidov et al. (2004)). This is also what we find in our experiments, as can be seen in the time-series in Fig. 2c) to obtain a coherent and significant Southern Hemisphere warming in a specific zone in our model (as is required by our method), a strong reduction in the northward component of the Atlantic heat transport is required. As we discussed above, this is true in experiments with large freshwater fluxes, but not in experiments with small ones. To evaluate the bipolar seesaw, we therefore need to select the simulations with stronger freshwater perturbation (i.e. above $20 \mathrm{cSv}$ to ensure a quasi-complete shutdown). We then apply the same method (cf. Sect. 6.1), taking the maximum warming over the Southern Ocean $\left(60-75^{\circ} \mathrm{S}\right)$ and we obtained the results plotted in Fig. 11. It should be noted that this maximum warming occurs much later than the Greenland cooling in our simulations: in average the difference between the two is on the order of 190 years, with a maximum lag of $\simeq 300$ years for the HRO ensemble. It is rather difficult to compare this value with the characteristic time lag of Antarctica with respect to Greenland as seen in the data: indeed, the short phase difference is less than the relative dating uncertainties from ice-cores in both areas (EPICA community members 2006) which is at least 400 years. The only conclusion we can safely draw is that data inferences and models results are not contradicting each other.

The first obvious difference between the anomaly plots on Fig. 11 is that the three different groups defined from Fig. 9 are still present in an almost identical configuration: LS \& SLO (Fig. 7c, d) are showing very little Southern Hemisphere warming, at an early time in the simulation (before the end of the pulse) and with a rather nonhomogeneous pattern around the Southern Ocean. This shows that when only the southernmost convection site in the North Atlantic is perturbed, there is still strong south to north heat transport via the Atlantic Ocean. The second group (FISM, RB, HRO, MRO \& CRO, Fig. 7a, b, e, g and h) shows the most widespread and consistent pattern of warming throughout the Southern Ocean, with warming up to $3^{\circ} \mathrm{C}$. While this number does not bear a strict meaning, it 
still indicates that warming of several degrees is present in most of the four experiments considered. The warming occurs much later in the experiment (generally 300 years), after the end of the freshwater perturbation. This indicates that one to two centuries are needed to build up a big warm anomaly in the Southern Hemisphere in our model. It should be noted that while the HRO experiments have a significant southern warm anomaly as late in the simulations as the other members of the second group, the pattern of warming is not so evident, making it an intermediate case between the first and second group. The largest anomalies are found in the experiments already showing a small warm anomaly at time of the maximum cold anomaly in Central Greenland, namely FISM, MRO \& $\mathrm{CRO}$, but also in the $\mathrm{RB}$ where the southern export of NADW is substantially reduced in more than $20 \mathrm{cSv}$ freshwater experiments (see Fig. 3).

In the same four experiments (FISM, MRO, CRO \& RB), there is also a substantial northeastern Pacific warming of up to $3^{\circ} \mathrm{C}$, which was already marginally present at time of maximum Greenland cooling (Fig. 6). Such a pattern can be linked both to the change in the atmospheric wave pattern as a consequence of the north Atlantic cooling and to the enhanced Pacific Ocean heat transport consecutive to the reduced north Atlantic Ocean heat transport.

In the case of the North Pacific freshwater forcing (LIMP) there is also some evidence of Southern Ocean warming (see Fig. 11i), occurring consistently throughout the experiments. Figure 3 conversely shows that adding freshwater to the LIMP increases the NADW export to the Southern Ocean. Indeed the cold anomaly over the northern Atlantic Ocean induced by Pacific sea-ice expansion helps increasing the NADW export to the Southern Hemisphere. After the end of the pulse, the NADW export recovers to pre-perturbed values. In our experiments, these modifications of the NADW export are forcing changes in the AABW by a compensation mechanism inducing the postpulse warming we observe in Fig. 11. A complete understanding of this compensation mechanism is beyond the scope of this study and will be investigated in more details in future work.

Finally, there is not much southern warming pattern in the AISM case, but some warming in the Northern Hemisphere, especially in the Labrador Sea region pointing towards changes in sea-ice cover in that area.

\section{Fingerprinting: a tentative comparison to Heinrich event 1 climate response}

Heinrich event 1 (H1) is the most recent glacial massive iceberg discharge event occurring just before the deglaciation and is probably one of the largest of the last glacial/ interglacial cycle (Hemming 2004). In this section, we will compare the climate fingerprints obtained from our systematic freshwater forcing study to available temperature data available for the time period encompassing H1. One should note that Heinrich events are defined as Ice Rafted Detritus (IRD) layers in the so-called Ruddiman Belt (roughly between 30 and $60^{\circ} \mathrm{N}$ in the North Atlantic) (Ruddiman 1977). Outside of this well-defined region, Heinrich events do not exist. Therefore, establishing a causal link between iceberg discharge events in the North Atlantic Ocean and climate signals in remote regions is not straightforward, especially when the precision of the relative dating between records is of the same order of magnitude as the signal observed. In the following, we will analyse temperature patterns from two recent data compilations (Kiefer and Kienast 2005; Genty et al. 2006). We paid attention to the fact that the reconstructed temperature anomalies are not necesarily triggered by $\mathrm{H} 1$ but are anomalies " at the time of H1 ". Therefore, this section should be understood as a first step towards a more extensive data compilation and data - model comparison which is beyond the scope of this study. Please note that our applied freshwater pulses are shorter than the actual H1 as it is recorded in North Atlantic sediments, implying that comparing the timing of our modelled response to data is not straight-forward. However, the patterns (fingerprints) should be comparable.

\subsection{A viewpoint from the Pacific Ocean}

As far as the oceans are concerned, it is evident from Fig. 9 and 11 that the region best suited to distinguish between the different patterns of freshwater forcing we have tested is not the North Atlantic. Indeed, most experiments yield similar temperature patterns there. On the contrary, other areas such as the northern Pacific Ocean, Siberia or the Arctic show a variety of responses. A published compilation of the available temperature records for the Pacific Ocean over the last deglaciation including the time period encompassing the H1 (Kiefer and Kienast 2005) shows that records can be classified in four categories (Kiefer and Kienast (2005, their Fig. 6) depending on their recorded climate signal over the deglaciation.

- First are regions of the Pacific Ocean where no deglacial climate events can be distinguished (continuous warming throughout the deglaciation), occurring in the central Pacific Ocean, along the Panama Isthmus, along the South American coast and close to Borneo in the region occupied today by the west Pacific warm pool. With respect to our experiments, this translates into an absence of signal in these regions both at time of maximum cooling in Greenland (Fig. 9) and at time 
of maximum warming around Antarctica (Fig. 11). All our experiments comply with such a requirement if we neglect coolings/warmings smaller than $0.5^{\circ} \mathrm{C}$ (which would fall below the resolution attainable by the records).

- Second are regions which show an early warming followed by a late cooling during the deglaciation, represented by one record south of $45^{\circ} \mathrm{S}$, along New-Zealand. For our concern, the time of $\mathrm{H} 1$, this would translate into regions showing no cooling or a warming at time of maximum Greenland cooling and also a warming at time of maximum warming around Antarctica. It would not correspond to about half of our tested regions: LS, SLO, HRO, AISM and GoM indeed do not show any evidence of warming in that area.

- Third is a belt extending from the Kamchatka region to Alaska-or even California, following the coast. This area is characterized by Kiefer and Kienast (2005) as showing a warm-cold oscillation during the $\mathrm{H} 1$ time frame, interpreted as showing a slow warming during the first part of the $\mathrm{H} 1$ time frame and a cooling in the second part. As our simulated pulses are shorter in timing than the $\mathrm{H} 1$ and consist of only one short pulse, it is difficult to translate this pattern to our experiments. We suggest here that it corresponds to a warming (at the very least an absence of cooling) during the coldest Greenland period (Fig. 9) and a cooling thereafter while Greenland is still cold. This does not seems to correspond to any of our simulations, though the first predicate might be associated with the north Pacific warming seen in FISM, MRO and GoM and to a lesser extent in RB, LS and SLO. Conversely, the LIMP response is rather contradictory with this data evidence. It should be noted that the small response for RB, LS and SLO is questionable, as during the deglaciation, the $\mathrm{H} 1$ is occurring under varying boundary conditions that could modify the obtained responses.

- Fourth, are regions where the response is in phase with Greenland, concentrated in the China sea. As for our experiments, such constraints points to FISM, RB, MRO \& $\mathrm{CRO}$ as the zones providing an equivalent response.

To summarize, comparison of a compilation of temperature records for the Pacific Ocean brings us to consider FISM, RB, MRO \& CRO as the zones where freshwater was entering the ocean at time of H1. It is comforting for our approach that the two zones corresponding to regions where we indeed find IRD (FISM, RB) stand out in this result, but also CRO which received input from the European ice-sheet at that time (Zaragosi et al. 2001).
7.2 Constraints from land records: speleothems from Eurasia

As far as land records are concerned, speleothems provide unique tools to access information about temperature and precipitation with a high dating accuracy thanks to U/Th chronologies. In a compilation of speleothems records from southern France to northern Tunisia combined with existing records from China, New-Zealand and South Africa, Genty et al. (2006) provides two important constraints with respect to freshwater-forced rapid climate changes at the end of the last glacial period. First, their work shows that the Northern Hemisphere respond in-phase at least as far south as $45^{\circ} \mathrm{N}$. Second they show that the two records from the Southern Hemisphere (New-Zealand and South Africa) are in phase with Antarctica and respond to the deglacial warming earlier than the Northern Hemisphere. It should be noted that Genty et al. (2006) stress this latter correlation as the most likely response, though the dating uncertainty is too high to ascertain it.

As for our experiments, we will therefore retain experiments in which the Northern Hemisphere signal from western Europe to China is in phase with Greenland and where South Africa and New-Zealand is coherent with the one in Antarctica. This leads us to consider FISM, RB, MRO, CRO \& LIMP. It should be noted that AISM is in clear contradiction with the two constraints we set from speleothems, as is GoM. We can therefore again stress the agreement between the zones retained after data-model comparison with the area where IRD are found during $\mathrm{H} 1$ (FISM, RB) and freshwater entered the ocean (CRO), while clearly rejecting some of the tested regions.

\section{Conclusions}

In summary, our experiments show that the climate system is most sensitive to freshwater perturbations originating from the three zones directly upstream from the north Atlantic deep oceanic convection sites: FISM, MRO, CRO. The RB experiment shows more or less the same pattern as for those for these zones, but with a reduced sensitivity, being more remote from these deep convection areas, and some of the freshening being carried southward in the surface subtropical gyre. Freshwater perturbations introduced in these regions lead in our model to large, Northern Hemisphere wide cooling and a later strong Southern Ocean warming, in accordance with the bipolar see-saw model (Crowley 1992; Broecker 1998; Seidov et al. 1998). Positive feedbacks involving sea-ice (i.e. ice-albedo, iceinsulation and seasonnality feedbacks) play an important role in producing these characteristic temperature anomaly patterns. Our model shows a much smaller sensitivity to 
freshwater pulses in the LS and SLO zones, with a much reduced cooling in the Northern Hemisphere and very little warming in the Southern Hemisphere. This is due to the mixing of the freshwater signal before reaching the deep convection sites, the advection there being much less efficient. Applying a freshwater perturbation over the north Pacific (LIMP) produces a large Northern Hemisphere cooling and a large Southern Hemisphere cooling, the mechanism for the latter being a complex interplay between the northern and southern deep water sources. Finally, the AISM experiments show a large cooling in the Southern Hemisphere with some (reduced in extension) cooling at the same time in the Northern Hemisphere, showing the non-symmetric nature of the bipolar see-saw mechanism. This conclusion is also true for the time of maximum warming (Fig. 11j)

Our results suggest that if a bipolar seesaw is observed in proxy records (e.g. in ice cores during specific D-O events or deglaciation (EPICA community members 2004)), this means that the northern convection site has been perturbed at that time, implying that the forcing most likely did not originate from GoM, LS, SLO or HRO, but rather from FISM, RB, MRO or CRO (or even LIPM).

A careful comparison with available temperature records for the time of the $\mathrm{H} 1$ corroborates that freshwater fluxes to the ocean likely originated from FISM, RB, CRO $\&$ MRO, whereas the patterns obtained for the other zones tend to contradict the pattern obtained from proxy data.

Acknowledgments D. M. Roche is supported by NWO under the RAPID project ORMEN. The authors would like to thanks D. Paillard, C. Van Meerbeeck and M. Kageyama for comments on an earlier version of the manuscript. We also thank P. Yiou and J. Servonnat for help regarding the statistical part of the analysis. The manuscript benefited from constructive reviews from $\mathrm{L}$. Tarasov and two anonymous reviewers.

Open Access This article is distributed under the terms of the Creative Commons Attribution Noncommercial License which permits any noncommercial use, distribution, and reproduction in any medium, provided the original author(s) and source are credited.

\section{References}

Broecker W, Andree M, Wolfli W, Oeschger H, Bonani G, Kennett J, Pete D (1988) The chronology of the last deglaciation: implications to the cause of the Younger Dryas event. Paleoceanography $3: 1-19$

Broecker WS (1998) Paleocean circulation during the last deglaciation: abipolar seesaw? Paleoceanography 13(2):119-121

Brovkin V, Ganopolski A, Svirezhev Y (1997) A continuous climatevegetation classification for use in climate-biosphere studies. Ecol Model 101:251-261

Crowley T (1992) North Atlantic deep water cools the southern hemisphere. Paleoceanography 7:489-497

Dokken T, Jansen E (1999) Rapid changes in the mechanism of ocean convection during the last glacial period. Nature 401:458-461
Driesschaert E, Fichefet T, Goosse H, Huybrechts P, Janssens I, Mouchet A, Munhoven G, Brovkin V, Weber SL (2007) Modelling the influence of the Greenland ice sheet melting on the Atlantic meridional overturning circulation during the next millennia. Geophys Res Lett 34:L10:707. doi:10.1029/2007GL029516

EPICA community members (2004) Eight glacial cycles from an Antarctic ice core. Nature 429:623-628

EPICA community members (2006) One-to-one coupling of glacial climate variability in Greenland and Antarctica. Nature 444:195198. doi:10.1038/nature05301

Eynaud F, Zaragosi S, Scourse J, Mojtahid M, Bourillet J, Hall I, Penaud A, Locascio M, Reijonen A (2007) Deglacial laminated facies on the NW European continental margin: the hydrographic significance of British-Irish Ice Sheet deglaciation and Fleuve Manche paleoriver discharges. Geochem, Geophys, Geosyst 8. doi:10.1029/2006GC00

Ganopolski A, Rahmstorf S (2001) Rapid changes of glacial climate simulated in a coupled climate model. Nature 409:153-158

Ganopolski A, Rahmstorf S, Petoukhov V, Claussen M (1998) Simulation of modern and glacial climates with a coupled model of intermediate complexity. Nature 391:351-356

Genty D, Blamart D, Ghaleb B, Plagnes V, Causse C, Bakalowicz M, Zouari K, Chkir N, Hellstrom J, Wainer K, Bourges F (2006) Timing and dynamics of the last delaciation from European and North African $\delta^{13} C$ stalagmite profiles-comparison with Chinese and South Hemisphere stalagmites. Q Sci Rev 25: 2118-2142. doi:10.1016/j.quascirev.2006.01.030

Goosse H, Fichefet T (1999) Importance of ice-ocean interactions for the global ocean circulation: a model study. J Geophys Res 104(C10):23,337-23,355. doi:10.1029/1999JC900215

Goosse H, Renssen H, Timmermann A, Bradley RS (2005) Internal and forced climate variability during the last millennium: a model-data comparison using ensemble simulations. Q Sci Rev 24:1345-1360. doi:10.1016/j.quascirev.2004.12.009

Hemming SR (2004) Heinrich events: Massive late Pleistocene detritus layers of the North Atlantic and their global climate imprint. Rev Geophys 42:RG1005. doi:10.1029/2003RG000128

Kiefer T, Kienast M (2005) Patterns of deglacial warming in the Pacific Ocean: a review with emphasis on the time interval of Heinrich event 1. Q Sci Rev 24:1063-1081. doi:10.1016/ j.quascirev.2004.02.021

Knorr G, Lohmann G (2003) Southern Ocean origin for the resumption of Atlantic thermohaline circulation during deglaciation. Nature 424:496-499

Labeyrie L, Duplessy JC, Duprat J, Juillet-Leclerc A, Moyes J, Michel E, Kallel N, Shackleton N (1992) Changes in the vertical structure of the North Atlantic ocean between Glacial and Modern times. Q Sci Rev 11:401-413

Manabe S, Stouffer R (1995) Simulation of abrupt climate change induced by freshwater input to the North Atlantic Ocean. Nature 378:65-167

Marshall S, Clarke G (1999) Modeling North American freshwater runoff through the last glacial cycle. Q Res 52:300-315. doi: 10.1006/qres.1999.2079

Meland MY, Dokken TM, Jansen E, Hevrøy K (2008) Water mass properties and exchange between the Nordic seas and the northern North Atlantic during the period $236 \mathrm{ka}$ : Benthic oxygen isotopic evidence. Paleoceanography 23:PA1210. doi: 10.1029/2007PA001416

Oppo DW, Lehman SJ (1993) Mid-depth circulation of the subpolar North Atlantic during the Last Glacial Maximum. Science 259(5098):1148-1152. doi:10.1126/science.259.5098.1148

Opsteegh J, Haarsma R, Selten F, Kattenberg A (1998) Ecbilt: adynamic alternative to mixed boundary conditions in ocean models. Tellus 50(A):348-367. http://www.knmi.nl/selten/tellus97. ps.Z 
Peltier W, Vettoretti G, Stastna M (2006) Atlantic meridional overturning and climate response to Arctic Ocean freshening. Geophys Res Lett 33:L06,713. doi:10.1029/2005GL025251

Petit JR, Jouzel J, Raynaud D, Barkov N, Barnola JM, Basile I, Bender M, Chapellaz J, Davis M, Delaygue G, Delmotte M, Kotlyakov V, Legrand M, VYLipenkov, Lorius C, Pepin L, Ritz C, Saltzman E, Stievenard M (1999) Climate and atmospheric history of the past 420,000 years from the Vostok ice core, Antarctica. Nature 399:429-436

Rahmstorf S (1995) Bifurcations of the Atlantic thermohaline circulation in response to changes in the hydrological cycle. Nature 378:145-149

Rahmstorf S, Crucifix M, Ganopolski A, Goosse H, Kamenkovich I, Knutti R, Lohmann G, Marsh R, Mysak L, Wang Z, Weaver A (2005) Thermohaline circulation hysteresis: amodel intercomparison. Geophys Res Lett 32:L23,605. doi:10.1029/2005GL023655

Renssen H, Goosse H, Fichefet T (2005) Contrasting trends in North Atlantic deep-water formation in the Labrador Sea and Nordic Seas during the Holocene. Geophys Res Lett 32:L08,711. doi: 10.1029/2005GL022462

Roche D, Paillard D, Cortijo E (2004) Constraints on the duration and freshwater release of Heinrich event 4 through isotope modelling. Nature 432:379-382

Roche D, Dokken TM, Goosse H, Renssen H, LWeber S (2007) Climate of the Last Glacial Maximum: sensitivity studies and model-data comparison with the LOVECLIM coupled model. Climate Past 3:205-244

Ruddiman W (1977) Late quaternary deposition of ice-rafted sand in the sub-polar north atlantic (lat $40^{\circ}$ to $65^{\circ}$ ). Geol Soc Am Bull $88: 1813-1821$

Saenko O, Weaver A, Robitaille D, Flato G (2007) Warming of the subpolar Atlantic triggered by freshwater discharge at the continental boundary. Geophys Res Lett 34:L15,604. doi: 10.1029/2007GL030674

Seidov D, Stouffer R, Haupt B (1998) The seesaw effect. Science 282:61-62

Seidov D, Stouffer R, Haupt B (2004) Strong hemispheric coupling of glacial climate through freshwater discharge and ocean circulation. Nature 430:851-856. doi:10.1038/nature02786

Seidov D, Stouffer R, Haupt B (2005) Is there a simple bi-polar ocean seesaw? Global Planet Change 49:19-27. doi:10.1016/j.gloplacha. 2005.05.001
Stommel H (1961) Thermohaline convection with two stable regimes of flow. Tellus 13:224-230

Stouffer R, Yin J, Gregory J, Dixon KW, Spelman M, Hurlin W, AJ Weaverand M Eby GF, Hasumi H, Hu A, Jungclaus J, Kamenkovitch I, Levermann A, Montoya M, Murakami S, Nawrath S, Oka A, Peltier W, Robitaille D, Sokolov A, Vettoretti G, Weber S (2006) Investigating the causes of the response of the thermohaline circulation to past and future climate changes. J Climate 19:1365-1387

Stouffer R, Seidov D, Haupt B (2007) Climate response to external sources of freshwater: North Atlantic versus the Southern Ocean. J Climate 20:436-448. doi:10.1175/JCLI4015.1

Tarasov L, Peltier W (2005) Arctic freshwater forcing of the Younger Dryas cold reversal. Nature 435:662-665. doi:10.1038/nature03617

Tarasov L, Peltier W (2006) A calibrated deglacial drainage chronology for the North American continent: evidence of an Arctic trigger for the Younger Dryas. Q Sci Rev 65:659-688. doi:10.1016/j.quascirev.2005.12.006

Tartinville B, Campin JM, Fichefet T, Goosse H (2001) Realistic representation of the surface freshwater flux in an ice-ocean general circulation model. Ocean Model 3:95-108

Trenberth K, Caron J (2001) Estimates of meridional atmosphere and Ocean heat transports. J Climate 14:3433-3443. doi:10.1175/ 1520-0442(2001)014

Vellinga M, Wood R (2002) The chronology of the last deglaciation: implications to the cause of the Younger Dryas event. Climatic Change 54:251-267

Weaver A, Saenko O, Clark P, Mitrovica J (2003) Meltwater pulse 1A from Antarctica as a Trigger of the Blling-Allerd warm interval. Science 299:1709-1713

Weber S, Drijfhout S, Abe-Ouchi A, Crucifix M, Eby M, Ganopolski A, Murakami S, Otto-Bliesner B, Peltier W (2007) The modern and glacial overturning circulation in the Atlantic ocean in PMIP coupled model simulations. Climate of the Past 2:923-949. doi: $1814-9359 / \mathrm{cpd} / 2006-2-923$

Wiersma AP (2008) Character and causes of the $8.2 \mathrm{ka}$ climate event. $\mathrm{PhD}$ thesis, Vrije Universiteit Amsterdam

Zaragosi S, Eynaud F, Pujol C, Auffret G, Turon J, Garlan T (2001) Initiation of the European deglaciation as recorded in the northwestern Bay of Biscay slope environments (Meriadzek Terrace and Trevelyan Escarpment): a multi-proxy approach. Earth Planet Sci Lett 188:493-507 